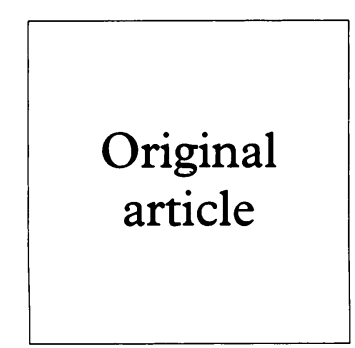

\section{Prevalence and risk factors for hepatitis B virus infections among visitors to an STD clinic}

\author{
Y T H P van Duynhoven, M J W van de Laar, W A Schop, Ph H Rothbarth, \\ W I van der Meijden, A $M$ van Loon, $M J$ W Sprenger
}

Objective: To determine the prevalence and risk factors for hepatitis B virus (HBV) infections among individuals attending an STD clinic in a low endemic region.

Study design: A total of 1228 women and 1648 men attending the STD clinic at the University Hospital Rotterdam, Netherlands, were examined for HBV infection by determination of hepatitis B surface antigen ( $\mathrm{HBsAg}$ ) and antibodies to hepatitis $\mathrm{B}$ core antigen (anti-HBc). Demographic characteristics, information on sexual behaviour, and intravenous drug use were recorded.

Results: The seroprevalence of HBsAg was $1 \cdot 4 \%$ in women and $2 \cdot 1 \%$ in men $(0 \%$ in homosexual men). The seroprevalence of anti-HBc was $13 \%$ in women and $20 \%$ in men $(36 \%$ in homosexual men). Native country, intravenous drug use, a history of STD, and the number of partners in the past half year (inversely) were independent risk factors for HBsAg positivity in women and heterosexual men. For anti-HBc independent associations were observed for native country, age, intravenous drug use, commercial sex, number of lifetime partners, homosexual contacts, orogenital contact (inverse), and a history of STD.

Conclusion: The HBV prevalence in the STD clinic attendants was high, exceeding the national estimate, and indicates that the STD clinic population may be considered a high risk group. Our data confirmed an increased risk for HBV infections among established risk groups. Therefore, these risk groups should be routinely screened to identify HBV cases for counselling and contact tracing.

(Genitourin Med 1997;73:488-492)

Keywords: hepatitis B virus infections; prevalence; risk factors

\section{Introduction}

In low endemic regions infections with hepatitis $B$ virus (HBV) occur predominantly in adults, largely as a result of sexual contact and parenteral transmission. ${ }^{12}$ About $5 \%-10 \%$ of the population will experience infection during their lifetime and less than $1 \%$ of adults are HBV carriers. ${ }^{1}$ In the Netherlands the estimated prevalence for $\mathrm{HBsAg}$ is $0.4 \%$, based on a screening programme for pregnant women. ${ }^{3}$ Like in other parts of Europe, the number of notified cases has declined considerably since the mid $1980 \mathrm{~s}^{45}$ This was mainly caused by reduction of risk behaviour and is only partially attributable to the effect of vaccination against hepatitis $B{ }^{4}$ At present, the control of HBV infections in the Netherlands includes counselling and contact tracing of HBV cases to prevent further transmission, targeted vaccination of high risk groups, and immunisation of children born to $\mathrm{HBsAg}$ positive mothers detected through a screening programme for pregnant women. ${ }^{36}$ Implementation of universal hepatitis $B$ vaccination into the Dutch immunisation programme is now under debate.

In the Netherlands, the prevalence and correlates of HBV infection in STD clinic populations were seldom documented because screening on HBV is not routine in these clinics. In 1994 a cross sectional study was carried out at the STD clinic of the University Hospital Rotterdam, which is the only STD clinic in the Netherlands with an ongoing universal screening for $\mathrm{HBV}$. The objective of the current study was (1) to assess the HBV prevalence among STD clinic attendants and (2) to identify risk factors for $\mathrm{HBV}$ infection in this population.

\section{Patients and methods}

STUDY POPULATION

In 1994 a cross sectional study was carried out among visitors to the STD clinic of the Department of Dermatology and Venereology, at the University Hospital of Rotterdam. The o following items were recorded on standardised forms: reason for visiting the clinic, specific urogenital complaints, and former experiences with STD; for women additional information was collected on their menstrual cycle and reproductive history. In addition, attendants were asked about age at first sexual intercourse, sex of sexual contacts, type (steady, casual, commercial) and sex of last and former sexual contact, the number of sexual partners in three periods (past month, half year, and lifetime), orogenital and anal contact in the past 6 months, and condom use while having intercourse with casual partners in the past 6 months. Also intravenous drug use (past 3 months, ever, or never) and either work as a prostitute or visit to a prostitute (past 3 months, ever, or never) was reported. Finally, participants were questioned about national- 
ity, native country, and use of antibiotics in the preceding 4 weeks. No information was collected on hepatitis specific complaints, vaccination status, and parenteral transmission routes other than intravenous drug use.

\section{LABORATORY TESTING}

From all visitors, blood samples were taken routinely for determination of (past) HBV infection. Assays included those for hepatitis B surface antigen (HBsAg) (MEIA, Abbott, Chicago, IL, USA) and for total antibodies to hepatitis $\mathrm{B}$ core antigen (anti-HBc) (MEIA) and were carried out at the Department of Virology, University Hospital Rotterdam. HBsAg positive results were confirmed either by a passive haemagglutination assay (Hepatest, Murex, Dartford) or a neutralisation MEIA (Abbott, Chicago, IL, USA) if the passive haemagglutination test was inconclusive. After confirmation of a positive $\mathrm{HBsAg}$, further MEIAs were performed for determination of antibodies to hepatitis $\mathrm{B}$ e antigen (anti-HBe) and for hepatitis $\mathrm{B}$ e antigen (HBeAg) (Abbott, Chicago, IL, USA). Sera which tested negative for $\mathrm{HBsAg}$ and positive for anti-HBc were tested for antibodies to hepatitis B surface antigen (anti-HBs) (MEIA). If sera were only positive for anti$\mathrm{HBc}$, additional tests for $\mathrm{HBeAg}$ and anti-HBe were to exclude a window phase after a recent infection.

\section{STATISTICAL ANALYSES}

Univariate analyses for HBsAg positivity and anti-HBc positivity were carried out, combined for men and women, by using the $\chi^{2}$ test or the two tailed Fisher exact test. Relevant associations with a $p$ value of $0 \cdot 10$ or less were further analysed by multiple logistic regression analysis to correct for confounding variables and to evaluate possible effect modification. Sex was always included in the model. A full model, including the main effects of the univariate analysis, was compared with models excluding every other factor. A factor remained in the model if either the likelihood ratio test was significant $(p<0.05)$ or the estimates of the $\beta$ coefficients for other variables in the model changed by at least $10 \%$. Odds ratios (OR) are presented with $95 \%$ confidence intervals $(\mathrm{CI})$.

Table 1 Prevalence of $H B s A g$ and anti-HBc among 2876 visitors of the STD clinic, University Hospital Rotterdam, 1994, by sex

\begin{tabular}{lllllll}
\hline & \multicolumn{2}{l}{ HBsAg positive } & & \multicolumn{2}{l}{ Anti-HBc positive } \\
\cline { 3 - 3 } \cline { 6 - 7 } & $n$ & & & $n$ & $\%$ \\
\hline Men & $\mathrm{n}=1648$ & $35^{\star}$ & $2 \cdot 1$ & & $322 \ddagger$ & $19 \cdot 5$ \\
Women & $\mathrm{n}=1228$ & $17 \dagger$ & $1 \cdot 4$ & & $160 \S$ & $13 \cdot 0$ \\
Total & $\mathrm{n}=2876$ & 52 & $1 \cdot 8$ & & 482 & $16 \cdot 8$ \\
\hline
\end{tabular}

$\star 33$ men were $\mathrm{HBsAg}$, anti- $\mathrm{HBc}$, and anti- $\mathrm{HBe}$ positive, one man was $\mathrm{HBsAg}, \mathrm{HBeAg}$, and anti$\mathrm{HBc}$ positive, and the remaining man was only $\mathrm{HBsAg}$ positive (serology of other $\mathrm{HBV}$ markers incomplete).

incomplete). †15 women were $\mathrm{HBsAg}$, anti-HBc, and
$\mathrm{HBsAg}, \mathrm{HBeAg}$, and anti-HBc positive.

$\ddagger$ For 34 of these men see above ${ }^{\star}$ regarding $\mathrm{HBsAg}$, for the remainder: 269 men were both anti$\mathrm{HBc}$ and anti-HBs positive, five men were anti-HBc and anti-HBe positive but anti-HBs negative, the remaining 14 men were only anti-HBc positive (for eight of them serology of other HBV markers was incomplete)

SFor 17 of these women see abovet regarding $\mathrm{HBsAg}$, for the remainder: 131 women were both anti-HBc and anti-HBs positive, six women were anti-HBc and anti-HBe positive but anti-HBs negative and the remaining six women were only anti-HBc positive (for four of them serology of HBV markers was incomplete)

\section{Results}

PATIENT POPULATION

Of the eligible population of 3277 individuals, 1696 men and 1288 women (2984 in total) were tested for at least one STD and were available for analyses $(91 \%)$. The remaining $9 \%$ were very similar to the study participants, although non-participants were born in the Netherlands more often and reported a history of STD as well as drug use and commercial sex contacts less often (data not shown). The mean age for men was 34.3 years and for women $29 \cdot 7$ years. About $60 \%$ were born in the Netherlands. Sixty three per cent of the men and $47 \%$ of the women presented at the clinic with urogenital symptoms. Of the women, an additional $10 \%$ attended the clinic because of the urogenital complaints of their sexual partners. About two thirds of the visitors were self referred, $18 \%$ of men and $12 \%$ of women were referred by their general practitioner, and $4 \%$ of men and $5 \%$ of women by a specialist doctor.

\section{PREVALENCE OF HBV MARKERS}

In all, $2876(96 \%)$ serum samples were examined for $\mathrm{HBV}$ infection. $\mathrm{HBsAg}$ was found in the blood of $17(1 \cdot 4 \%)$ women and $35(2 \cdot 1 \%)$ men (table 1). Of these, two women and one man were also $\mathrm{HBeAg}$ positive. Four men were known $\mathrm{HBsAg}$ carriers. In addition, 160 women $(13.0 \%)$ and 322 men (19.5\%) were anti-HBc positive, indicating past $\mathrm{HBV}$ infection.

\section{RISK FACTORS FOR HBSAG POSITIVITY AND} ANTI-HBC

No association between $\mathrm{HBsAg}$ positivity and age or sex was found, but anti-HBc was higher in men and increased steadily with age (table 2). Very strong associations were found for native country. Both $\mathrm{HBsAg}$ and anti-HBc were more prevalent among visitors born in Surinam, Morocco, or Turkey and particularly among the relatively small group from Cape Verde. The remaining foreign born visitors (about $85 \%$ born in high and middle endemic regions such as sub-Saharan Africa, Asia, Dutch Antilles, Middle/South America, eastern Europe, and Mediterranean countries) were also at increased risk for positive HBV markers. Individuals currently using intravenous drugs were also more often $\mathrm{HBsAg}$ positive or anti-HBc positive. For anti-HBc this also accounted for those with a history of drug use.

HBsAg was not observed among homosexuals (compared with $1.9 \%$ for heterosexuals and $3 \cdot 1 \%$ for bisexuals). However, the anti$\mathrm{HBc}$ prevalence of $35.8 \%$ was the highest for this group compared with $14.9 \%$ among heterosexuals and $26 \%$ for bisexuals. Individuals reporting commercial sex (work or visit) tended to have a high $\mathrm{HBsAg}$ and anti-HBc prevalence, but even higher rates were found among those without information on commercial sex (table 2). An inverse relation for $\mathrm{HBsAg}$ with the number of partners in the past half year was suggested, although this trend was not statistically significant. Anti- 
Table 2 Univariate analyses of patient characteristics for $\mathrm{HBs} A \mathrm{~g}$ positivity and anti-HBc positivity among 2876 visitors of the STD clinic, University Hospital Rotterdam, 1994

\begin{tabular}{|c|c|c|c|c|c|}
\hline $\begin{array}{l}\text { Patient characteristics } \\
\text { Total }\end{array}$ & $\begin{array}{l}\text { Number' } \\
2876\end{array}$ & $\underset{1 \cdot 8 \%}{\mathrm{HBS} A g}$ & $\begin{array}{l}\text { OR } \mathrm{HBs} A \mathrm{~g} \\
95 \% \mathrm{CI}\end{array}$ & $\begin{array}{l}\text { anti-HBc } \\
16 \cdot 8 \%\end{array}$ & $\begin{array}{l}\text { OR anti-HBc } \\
95 \% \mathrm{CI}\end{array}$ \\
\hline \multicolumn{2}{|l|}{ Sex: } & $\star$ & & $\star \star \star \star$ & \\
\hline Men & 1648 & $2 \cdot 1$ & $1.5(0.9-2.8)$ & $19 \cdot 5$ & $1 \cdot 6(1 \cdot 3-2 \cdot 0)$ \\
\hline Women & 1228 & $1 \cdot \overline{4}$ & $1 \cdot 0$ & $13 \cdot 0$ & 1.0 \\
\hline \multicolumn{2}{|l|}{ Age (years): } & & & $\star \star \star \star$ & \\
\hline $11-19$ & 187 & $0 \cdot 0$ & - & $6 \cdot 4$ & $0 \cdot 6(0 \cdot 3-1 \cdot 1)$ \\
\hline $20-24$ & 531 & $1 \cdot 7$ & $1 \cdot 0$ & 10.9 & $1 \cdot 0$ \\
\hline $25-29$ & 664 & $2 \cdot 0$ & $1.2(0.5-2.7)$ & $13 \cdot 3$ & $1.2(0.9-1.8)$ \\
\hline $30-34$ & 583 & $2 \cdot 4$ & $1.4(0.6-3 \cdot 3)$ & $16 \cdot 6$ & $1 \cdot 6(1 \cdot 1-2 \cdot 3)$ \\
\hline$\geqslant 35$ & 911 & $1 \cdot 8$ & $1 \cdot 0(0.5-2 \cdot 4)$ & $24 \cdot 9$ & $2 \cdot 7(2 \cdot 0-3 \cdot 7)$ \\
\hline \multicolumn{2}{|l|}{ Native country: } & & & & \\
\hline Netherlands & 1701 & 0.4 & $1 \cdot 0$ & 8.9 & $1 \cdot 0$ \\
\hline Surinam/Morocco/Turkey & 566 & $4 \cdot 1$ & $10 \cdot 6(4 \cdot 5-24 \cdot 8)$ & $22 \cdot 4$ & $3 \cdot 4(2 \cdot 7-4 \cdot 3)$ \\
\hline Cap Verde & 66 & $9 \cdot 1$ & $25 \cdot 0(8 \cdot 1-76 \cdot 6)$ & $47 \cdot 0$ & $8 \cdot 4(5 \cdot 1-14 \cdot 0)$ \\
\hline Other countries & 488 & $3 \cdot 3$ & $8.5(3.5-20 \cdot 7)$ & $27 \cdot 7$ & $3 \cdot 6(2 \cdot 8-4 \cdot 7)$ \\
\hline \multicolumn{2}{|l|}{ Intravenous drug use: } & & & & \\
\hline Never & 2406 & 1.6 & $1 \cdot 0$ & $15 \cdot 3$ & \\
\hline Past 3 months & 108 & $4 \cdot 6$ & $2.9(1 \cdot 1-7 \cdot 6)$ & $39 \cdot 8$ & $3 \cdot 7(2 \cdot 5-5 \cdot 5)$ \\
\hline Ever (> 3 months ago) & 98 & $1 \cdot 0$ & $0.6(0 \cdot 1-4 \cdot 6)$ & $32 \cdot 7$ & $2 \cdot 7(1 \cdot 7-4 \cdot 2)$ \\
\hline \multirow{2}{*}{\multicolumn{2}{|c|}{ Commercial sex (work or visit): }} & $2 \cdot 7$ & $1.7(0.7-3.7)$ & $15 \cdot 2$ & $1 \cdot 0(0 \cdot 7-1 \cdot 4)$ \\
\hline & & $\star \star$ & & $\star \star \star \star 厶$ & \\
\hline Never & 1806 & $1 \cdot 3$ & & $13 \cdot 2$ & $1 \cdot 0$ \\
\hline Past 3 months & 400 & $2 \cdot 3$ & $1 \cdot 8(1 \cdot 0-3 \cdot 3)$ & $21 \cdot 3$ & $1 \cdot 9(1 \cdot 6-2 \cdot 4)$ \\
\hline Ever ( $>3$ months ago) & 510 & $2 \cdot 6$ & & $23 \cdot 7$ & \\
\hline Unknown & 160 & $3 \cdot 8$ & $2 \cdot 9(1 \cdot 2-7 \cdot 2)$ & $23 \cdot 1$ & $2 \cdot 0(1 \cdot 3-2 \cdot 9)$ \\
\hline \multicolumn{2}{|l|}{ Number of partners past half year: } & $\star \star$ & & $\star \star \star \star$ & \\
\hline 0 & 136 & $4 \cdot 4$ & $2 \cdot 2(0 \cdot 9-5 \cdot 4)$ & $19 \cdot 9$ & $1.5(0.9-2 \cdot 3)$ \\
\hline 1 & 1356 & $2 \cdot 1$ & 1.0 & 14.5 & $1 \cdot 0$ \\
\hline 2 & 685 & 1.0 & $0.5(0.2-1 \cdot 1)$ & $13 \cdot 6$ & $0.9(0.7-1 \cdot 2)$ \\
\hline$\geqslant 3$ & 542 & 1.9 & $0.9(0.4-1.8)$ & $23 \cdot 4$ & $1 \cdot 8(1 \cdot 4-2 \cdot 3)$ \\
\hline \multirow{2}{*}{\multicolumn{2}{|c|}{$\begin{array}{l}\text { Unknown } \\
\text { Condom casual partners past half year: }\end{array}$}} & 0.6 & $0.3(0.04-2.3)$ & 24.8 & $2 \cdot 0(1 \cdot 3-2 \cdot 9)$ \\
\hline & & $\star \star \star \star 2$ & & $\star$ & \\
\hline \multirow{5}{*}{$\begin{array}{l}\text { Never, sometimes, half the times } \\
\text { Mostly }(60-95 \%) \text { or always } \\
\text { No casual partners reported } \\
\text { Unknown } \\
\text { Orogenital contact in past half year: }\end{array}$} & 740 & $2 \cdot 3$ & $2 \cdot 6(1 \cdot 0-6 \cdot 5)$ & $19 \cdot 2$ & $1 \cdot 0(0 \cdot 7-1 \cdot 3)$ \\
\hline & 657 & 0.9 & & $18 \cdot 6$ & \\
\hline & 1315 & $2 \cdot 1$ & $2.3(0.9-5.5)$ & $14 \cdot 4$ & $0.7(0.5-0.9)$ \\
\hline & 164 & $1 \cdot 2$ & $1 \cdot 3(0 \cdot 3-6 \cdot 7)$ & $17 \cdot 7$ & $0.9(0.6-1.4)$ \\
\hline & & $\star \star \star \star$ & & $\star \star \star \star$ & \\
\hline \multirow{2}{*}{$\begin{array}{l}\text { No } \\
\text { Yes }\end{array}$} & 1167 & $2 \cdot 9$ & $1 \cdot 0$ & $20 \cdot 4$ & $1 \cdot 0$ \\
\hline & 1552 & $1 \cdot 2$ & $0.4(0.2-0.8)$ & $13 \cdot 5$ & $0.6(0.5-0.7)$ \\
\hline \multicolumn{2}{|l|}{ History of STD: } & $\star \star \star \star$ & & $\star \star \star$ & \\
\hline No & 1601 & $1 \cdot 1$ & $1 \cdot 0$ & $12 \cdot 9$ & 1.0 \\
\hline Yes & 1247 & $2 \cdot 7$ & $2.5(1.4-4.4)$ & $21 \cdot 7$ & $1.9(1.5-2.3)$ \\
\hline
\end{tabular}

$\star \star \star=P<0.05,{ }^{\star \star}=\mathrm{P}<0.10,{ }^{\star}=\mathrm{P} \geqslant 0.10$ for either $\chi^{2}$ or Fisher exact test.

'Totals do not always add to this number because of missing values.

${ }^{2}$ The $\chi^{2}$ test was restricted to those with casual partners and information on condom use.

Table 3 Multiple logistic regression analyses for $\mathrm{HBs} \mathrm{Ag}$ and anti-HBc among 2876 visitors of the STD clinic, University Hospital Rotterdam, 1994

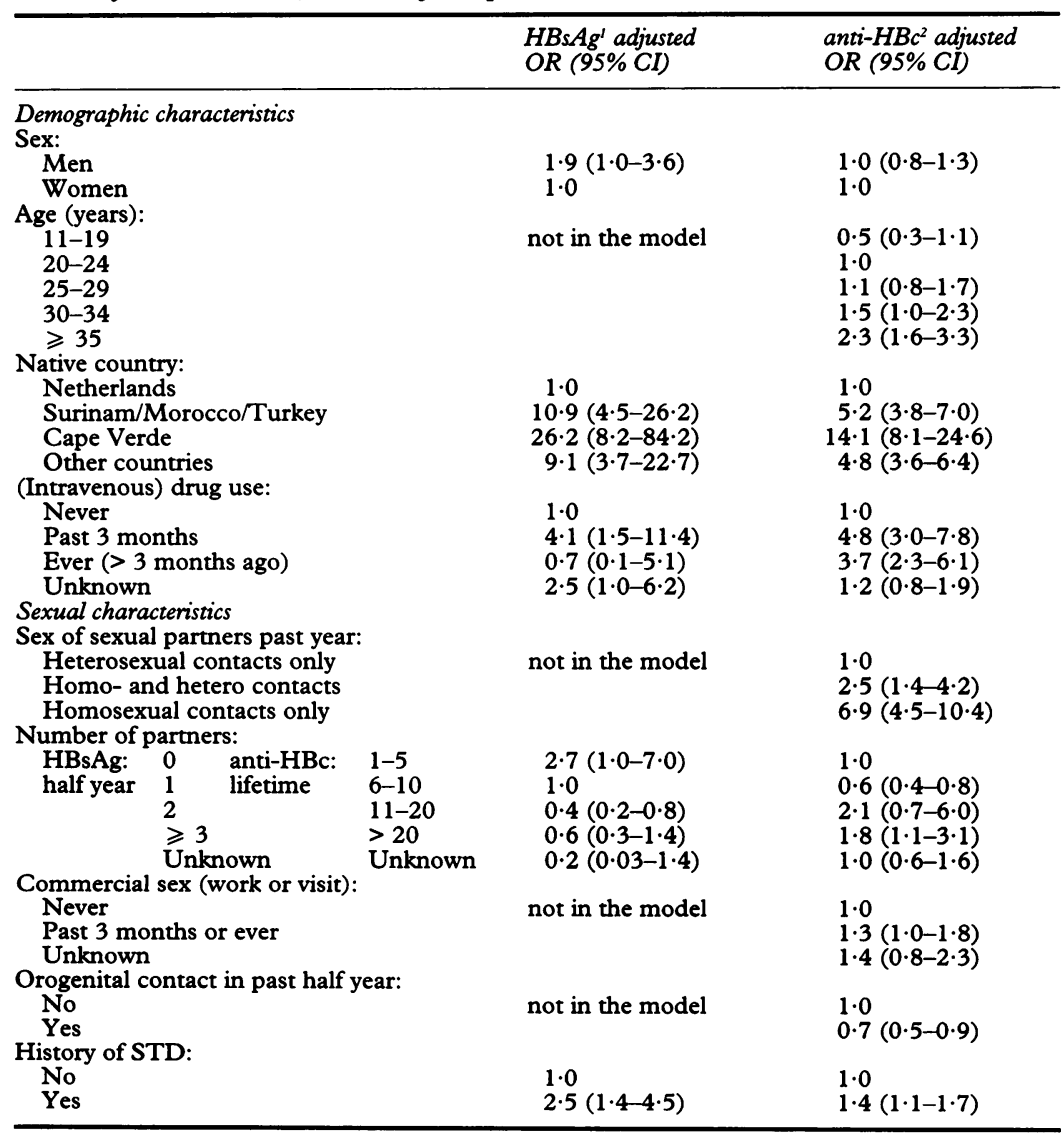
three or more sexual partners in the past half year. The same was found when the number of partners in the past month or during lifetime (more than 10) was considered (data not shown). Use of condoms in less than $60 \%$ of casual contacts in the past half year was associated with $\mathrm{HBsAg}$ positivity compared with more frequent use of condoms, but no association with anti-HBc was found (table 2). For both HBV markers a protective effect was found for orogenital contact in the past half year. A history of STD was associated with a higher prevalence of $\mathrm{HBsAg}$ and anti-HBc. Finally, no associations with $\mathrm{HBsAg}$ were found for age at first sexual intercourse, a steady relationship, the type of partner during last and former sexual contact, anal contact in the past 6 months, and the number of partners in the past month and during lifetime. For anti-HBc no relevant associations were observed for age at first sexual intercourse, a steady relationship, and the type of partner during last and former sexual contact.

MULTIPLE LOGISTIC REGRESSION

For HBsAg homosexuals were excluded from the multiple regression analyses. The final logistic model included (table 3) sex, native country, intravenous drug use, the number of partners in the past half year, and a history of STD. The ORs were very similar to those found in the univariate analyses (including the homosexuals), with the exception of a rise in

${ }^{1} 174$ homosexual men excluded (HBsAg prevalence was $0 \%$ in this group) -2 log likelihood

presented model $(n=2663, \% \mathrm{HBsAg}=2 \cdot 0): 427 \cdot 1, \mathrm{df}=12, \mathrm{p}=0 \cdot 0001$.
${ }^{2}-2 \log$ likelihood presented model $(\mathrm{n}=2774, \%$ anti-HBc $=16 \cdot 6): 2032 \cdot 8, \mathrm{df}=19, \mathrm{p}=0.0001$. the OR for recent drug use from $2 \cdot 9$ to $4 \cdot 1$. 
This was mainly due to correction for native country; because $8 \%$ of the Dutch visitors reported drug use, compared with $1 \%$ to $4 \%$ of the (highly infected) foreign born visitors, Dutch were overrepresented among the intravenous drug users.

For anti-HBc all risk factors were kept in the model (table 3). However, sex was no longer associated with anti-HBc after adjustment for the effect of other risk factors. All the ORs increased except for sex, commercial sexual contacts, and the history of STD. When the number of lifetime partners was substituted for those in the past half year no association with the number of partners was found.

\section{Discussion}

This study estimated the prevalence and identified risk factors for $\mathrm{HBV}$ infections among STD clinic attendants. Both the seroprevalence of $\mathrm{HBsAg}$ and anti-HBc among attendants of the STD clinic were high and exceeded the estimated national prevalence of $0.4 \%$ for $\mathrm{HBsAg}$ and less than $10 \%$ for antiHBc. ${ }^{13}$ Therefore, the STD clinic population can be considered a high risk group for HBV infections. The $\mathrm{HBsAg}$ rate of $1.8 \%$ is within the range of the $0.2 \%$ and $5 \%$ found by others. ${ }^{8}$ The prevalence of anti-HBc also correspond well with other studies in similar settings. ${ }^{8-10}$ However, our HBsAg and anti$\mathrm{HBc}$ prevalences may be slightly underestimated because vaccinated individuals could not be identified and excluded from the denominator. On the contrary, the low risk character of the non-participants in this study might have caused a minor overestimation of the HBV prevalence.

Increased rates of $\mathrm{HBV}$ markers were observed among individuals born in intermediate and high endemic countries and to a lesser extent among intravenous drug users, homosexuals, those with multiple partners or commercial sexual contacts, or a history of STD. The high prevalence for the ethnic minorities was probably due to infection at birth or early in life, as the most likely transmission routes in these regions, with a higher probability of developing to chronic asymptomatic infection. ${ }^{111}$ Ethnic differences in the prevalence of HBV markers were also noticed in the STD clinic in Amsterdam, Netherlands, ${ }^{10}$ in an STD clinic in Copenhagen, Denmark, ${ }^{12}$ and in two STD clinics in the West Midlands. ${ }^{13}$

Although the seroprevalence of $\mathrm{HBsAg}$ was $0 \%$ in homosexuals, the high anti-HBc rate illustrated an increased risk for this group. Absence of HBsAg could be due to chance or may be explained by immunity as a result of previous HBV infection, reduction of high risk behaviour, and vaccination.

Our study demonstrated a negative association for HBsAg and the number of partners in the past half year, while in other studies positive associations were reported. ${ }^{2}$ This finding may be due to confounding by non-measured parenteral transmission routes. Also, the 6 month period for reported sexual activity could be less appropriate for assessing relevant exposure to HBV. None the less, the high anti$\mathrm{HBc}$-rates among those with multiple partners in addition to the high HBV prevalence among individuals who suffered from an STD corresponds well with others ${ }^{2}$ and suggests that sexual transmission is of importance in this population.

HBV infections at the STD clinic were mainly observed among established risk groups. Therefore, homosexual men, intravenous drug users, individuals with multiple partners, individuals with commercial sexual contacts, those with a history of STD, and those born in endemic countries should be routinely screened at STD clinics for case finding. Counselling of the $\mathrm{HBsAg}$ positive patient and tracing sexual and household contacts should be performed routinely to inform about the potential risk of $\mathrm{HBV}$ and to offer vaccination if appropriate. If, at this clinic, screening was restricted to the risk groups, $96 \%$ of the anti-HBc positives and $98 \%$ of the HBsAg positives would have been detected. However, as these risk groups already represented $76 \%$ of the total clinic population, universal screening is recommended, corresponding with the current policy.

The high prevalence, the apparent risk factors, and the large absolute number of high risk individuals in the STD clinic population in Rotterdam might suggest the potential of STD clinics in reaching risk groups for targeted vaccination, as earlier suggested by United Kingdom data on STD clinic attendance. ${ }^{14} \mathrm{~A}$ more adequate vaccination approach seems warranted by the current low vaccination coverage for sexual partners of HBsAg positive individuals, homosexual men, prostitutes, and intravenous drug users in the Netherlands. ${ }^{7}$ However, to determine the suitability of STD clinics as places for HBV vaccination, further studies are needed on HBV incidence, STD clinic attendance of high risk individuals, costs, and other aspects affecting the success of vaccination. ${ }^{15-18}$

This study was supported by the Ministry of Health, Welfare and Sports (research project 441501). The authors thank all medical, nursing, and clerical staff of the University Hospita Rotterdam STD clinic for their cooperation in the study.

1 Maynard JE, Kane MA, Alter MJ, Hadler SC. Control of hepatitis $B$ by immunization: Global perspectives. In Zuckerman AJ, ed. Viral hepatitis and liver disease. New York: Alan R Liss, 1988:967-9.

2 Alter MJ, Margolis HS. The emergence of hepatitis B as a sexually transmitted disease. Med Clin North Am 1990 74:1529-41

3 Grosheide PM, Klokman-Houweling JM, Conyn van Spaendonck MAE and the National Hepatitis B Steering Committee. Programme for preventing perinatal hepatitis B infection through screening of pregnant women and tis $B$ infection through screening of pregnant women and immunisation of infants of infected mother

4 Iwarson S, Jilg W, Stroffolini T. Substantial decline of notified hepatitis B in major parts of Europe after 1985 Scand $\mathcal{f}$ Infect Dis 1994;26:19-22.

5 Notified cases of hepatitis B registered at the Inspectorate for Health Care, 1981-1994.

6 Health Council of the Netherlands. Advice concerning hepatitis B. 's-Gravenhage: Health Council of the Netherlands, 1983; publication no 1983/22. [in Dutch]

7 Health Council of the Netherlands: Committee Hepatiti B. Protection against hepatitis B Rijswijk: Health Council of the Netherlands, 1996; publication . Health Council Dutch]

8 Stary A, Kopp W, Heller-Vitouch C. Coincidence of hepatitis B-virus markers and other sexually transmitted diseased in different Microbiol Virol Parasitol Infect Dis 1992;276:548-55. 
9 Barrett CL, Austin H, Louv WC, Alexander WJ, Hadler SC. Risk factors for hepatitis $B$ virus infection among women attending a clinic for sexually transmitted diseases. Sex Transm Dis 1992;19:14-8.

10 Doornum GJ van, Haastrecht HJA van, Hooykaas C, Hoek JAR van den, Linden MMD van der, Coutinho RA. Hepatitis B virus infection in a group of heterosexuals with multiple partners in Amsterdam, the Netherlands: implications for vaccination? $\mathcal{f} \mathrm{Med}$ Virol 1994;43:20-7.

11 McMahon BJ, Alword WH, Hall DB, Heyward WL, Bender ThR, Francis DP, et al. Acute hepatitis B virus infection: relation of age to the clinical expression of disease and subsequent development of the carrier state. $\mathcal{F}$ Infect Dis 1985;151:599-603.

12 Kvinesdal BB, Worm A-M, Gottschau A. Risk factors for hepatitis $B$ virus infection in heterosexuals attending venereal disease clinic in Copenhagen. Scand $\mathcal{f}$ Infect Dis 1993;25:171-5.

13 El-Dalil AA, Jayaweera DT, Walzman M, Radcliffe KW, Richmond $\mathrm{R}$, Wade AA, et al. Hepatitis $B$ markers in het- erosexual patients attending two genitourinary medicine clinics in the West Midlands. Genitourin Med 1997;73 127-30.

14 Johnson AM, Wadsworth J, Wellings J, Field J. Who goes to sexually transmitted disease clinics? Results from national population survey. Genitourin Med 1996;72: 197-202.

. ing for markers at a sexually transmitted disease clinic for men. Can $\mathcal{F}$ Public Health 1994;85:338-41.

16 Bhati N, Gilon RIC, Beecham M, Williams P, Matthews MP, Tedder RS, et al. Failure to deliver hepatitis B vaccine: confessions from a genitourinary medicine clinic. cine: confessions from

17 Weinstock HS, Bolan G, Moran JS, Peterman TA, Polish $\mathrm{L}$, Reingold AL. Routine hepatitis $\mathrm{B}$ vaccination in a clinic for sexually transmitted diseases. Am $\mathcal{f}$ Public Health 1995;85:846-9.

18 Asboe D, Rice P, Ruiter A de, Bingham JS. Hepatitis B vaccination schedules in genitourinary medicine clinics. Genitourin Med 1996;72:210-2. 